\title{
Modeling and Mapping of Urban Sprawl Pattern in Cairo Using Multi-Temporal Landsat Images, and Shannon's Entropy
}

\author{
Hala A. Effat, Mohamed A. El Shobaky \\ Division of Environmental Studies and Land Use, National Authority for Remote Sensing and Space \\ Sciences (NARSS), Cairo, Egypt \\ Email: haeffat@yahoo.com, heffat@narss.sci.eg
}

Received 14 October 2015; accepted 11 December 2015; published 14 December 2015

Copyright $@ 2015$ by authors and Scientific Research Publishing Inc.

This work is licensed under the Creative Commons Attribution International License (CC BY). http://creativecommons.org/licenses/by/4.0/

(c) (1) Open Access

\begin{abstract}
Cairo city, being the Egypt's industrial and cultural center, has a problem of rapid urban sprawl. The city has an extremely high population density which is continuously increasing through informal settlements that grow by sprawling due to migration from the Nile Delta villages and the high population growth rates. The present study attempts to understand, detect and quantify the spatial pattern of Cairo's urban sprawl using Shannon's entropy and multi-temporal Landsat TM and ETM images acquired for the period from 1984 to 2013. Supervised classification was applied to extract the built-up areas and to measure the changes in the urban land-use class among the city wards. Shannon's entropy was applied to model the city's urban sprawl, trend and spatial change. The entropy values for the city's electoral wards were modeled and used in an interpolation function to create an entropy surface (index) for each acquired temporal image. Such index indicates the spatial pattern of the urban sprawl and provides a visual comparison of the entropy phenomenon in such wards. Results indicate that Shannon's entropy index increased from (1.4615) in year 1984 to (2.1023) in year 2013, indicating more dispersed urban growth, a sign of urban sprawl. The maximum entropy values are found in the eastern wards namely El Nozha, Awal Nasr District, Thany Nasr-District, El Salam, El Marg and El Bassatein. A regression analysis was carried for the population growth rate and the built-up areas. Findings help in understanding the sprawl patterns and dynamics among Cairo's electoral wards and provide a visual comparison. The applied methodology provides explanations and facilitates tracing and measuring the urban sprawl which is needed by decision makers and city planners of mega cities.
\end{abstract}

\section{Keywords}

Shannon's Entropy, Urban Growth, Sprawl Patterns, Landsat, Cairo, Egypt 


\section{Introduction}

The term urban sprawl refers to the excessive and uncontrolled expansion of urban areas, which causes a wide range of social and environmental problems and has become a major concern for urban planners and policy makers in the developed and developing world (Brueckner, 2000 [1]; Frenkel and Ashkenazi, 2007 [2]; Knaap et al., 2013[3]). Sudhira et al., 2004 [4] describe the term Urban sprawl as the extent of urbanization, which is a global phenomenon mainly driven by population growth and large scale migration. Critics of sprawl all over the world are concerned by its many alleged negative impacts, such as a lack of scale economies, which reduces the level of public services in the suburbs and weakens the economic base of central cities; increased energy consumption through encouragement of the use of private vehicles, causing traffic congestion and air pollution; and irreversible damage to ecosystems, caused by scattered and fragmented urban development in open lands (Brueckner, 2000 [1]; Johnson 2001 [2]; Frenkel and Ashkenazi, 2008 [3]).

\subsection{Modeling of Urban Sprawl}

Unfortunately, the conventional surveying and mapping techniques are expensive and time consuming for the estimation of urban sprawl. As a result, increased research interest is being directed to the mapping and monitoring of urban sprawl/growth using GIS and remote sensing techniques. Post classification comparison is the most commonly used quantitative method of change detection. It involves independently produced classification results from each end of the time interval of interest, followed by a pixel by- pixel or segment-by-segment comparison to detect changes in cover classes. GIS and remote sensing are land related technologies and are therefore very useful in the formulation and implementation of the land related component of the sustainable development strategy. Kayhko and Skanes (2005) [5] performed retrospective landscape change trajectory analysis with the help of available spatio-temporal data of different time era and verified it with the help of the field data. Such data were taken to the GIS environment and compiled to detect the path of change of trajectory analysis. Junge et al. (2009) [6] find out that the increase in population density of Nigeria and Benin leads to the change in land use/land cover and also intensify the soil loss, forest degradation, plant and animal species reduction. Verzosa and Gonzalez (2010) [7] studied the land use changes in the mountainous city of Baguio in northern Philippines. Their study shows that together with remote sensing, geographic information systems and photogrammetric techniques, built-up concentration can be identified and quantified from time series of aerial photographs and satellite images. This facility can assist in monitoring the growth of built-up areas and in drafting measures and policies to address urban sprawl's imminent effects. They studied that the use of Shannon's Entropy is the attractive methodology in urban sprawl study and management, as entropy shows both dispersion and compactness. Bhatta et al. (2010) [8] studied the urban sprawl measurement with the help of remote sensing where conceptual ambiguity of sprawl and lack of consensus among researchers have made the measurement of urban sprawl very difficult. There are many scales and parameters that are in use to quantify the sprawl; however. many of them are suffered from several limitations. Pocas et al. (2011) [9] used three different temporal satellite images of the same area and find out the different types of vegetation, barren/fellow lands and used land and used landscape matrices to characterize the spatial heterogeneity, fragmentation and complexity of the landscape. From these studies it is clear that remote sensing and GIS may be used as useful tool to study the urban sprawl as it decrease the cost of data generation and also saves time.

In the recent years a lot of thrust in this field has been used to understand and analyze the urban sprawl pattern. Various analysts have made considerable progress in quantifying the urban sprawl pattern (Batty et al. 1999 [10]; Torrens and Alberti, 2000 [11]; Yeh and Li, 2001 [12]; Theobald, 2001 [13]; Barnes et al., 2001 [14]; Sudhira et al., 2004 [4]; Wei et al., 2006 [15]; Yu and Ng, 2006 [16]; Schneider, 2008 [17]; Singh, 2014 [18]). However most of these studies have come up with different methodologies in quantifying sprawl. A common approach is to consider the behavior of built-up area and population density over the spatial and temporal changes taking place and in most cases the pattern of such sprawls is identified by visual interpretation methods. Defining this dynamic phenomenon with relative precision and accuracy for predicting the future sprawl is indeed a great challenge to all working in this arena. Much of the work related to studying dynamics of urban sprawl are not carried out in the developing countries. Thus giving very little relevance to correlate the available findings in the context of developed countries. However the negative impacts of such urban sprawls in the developing countries are more severe and intense compared to that of developing countries. Typically, the developing countries are faced with an unprecedented population growth, informal urban growth and potentially threatened natural re- 
sources. Therefore, there is definitely a need to study, characterize and model the urban sprawl phenomenon in the context of developing countries. This work is an attempt in such exploration and understanding of the urban sprawl phenomenon and pattern recognition in the fast growing city of Cairo.

\subsection{Urban Sprawl Problem in Cairo}

In Egypt, high rates of natural increase partly account for rapid urban growth rates. In 1907 the inhabitants of urban areas accounted for 19 per cent of the total Egyptian population, rising to 33 per cent in 1947, 43 per cent in 1976, and 44 per cent in 1986. Cairo has been deeply transformed by the global dynamics of urbanization, which have increased the city's population by more than six times in the past 60 years. The problems of the city's "urban excess" [19] (Denis, 1996), which includes traffic, pollution, infrastructure that is inadequate to the needs of its nearly 20 million inhabitants, and the increasing dominance of informal over formal residential patterns. Rural-urban migration has been the major driving force behind urbanization in Egypt. The origin of this process of urban in formalization is to be found in the 1960s and 1970s when Cairo, witnessed the emergence of a peripheral form of urbanization. Nevertheless, the Egyptian laws forbid encroachment on agricultural land, yet, due to the fact that housing demand was still growing because of migration and high demographic growth in the capital, such lows failed to control the urban sprawl in and around the city. Informality became the solution to the housing needs of the city's lower and middle classes. Between 1986 and 1996, the demographic growth rate of informal settlements reached $3.4 \%$ per year compared to $0.3 \%$ for legal areas, and informal construction growth was estimated to be 3.2\% per year, compared to 1.1\% in formal districts [20] (Denis and Séjourné, 2002); Cairo City 2014 population is estimated 12 million. This condition resulted from the deterioration of rural areas as well as from the concentration of economic activities (and hence employment opportunities), services, political power, and wealth in the major urban centers and mainly in Cairo. On the other side, the overpopulation of the Cairo city is causing massive problems. Examples are traffic jam, streets blocked with private cars, exceeding the carrying capacity of the infrastructure lead to its inefficiency, in addition to social and economic problems. For a better planning of future urban development and infrastructure planning, municipal authorities need to know about the urban sprawl phenomenon and in what way it is likely to move in the following years.

\subsection{Objectives}

The main objective of the current study is to examine the dynamic phenomenon of urban sprawl/growth and pattern in the highly populated city of Cairo. The findings may help in studying some of the motivations and spatial patterns of the urban growth in Cairo.

The steps followed to cover the main objectives includes:

Mapping land use-land cover changes using satellite imageries to measure the urban growth.

Applying Shannon's entropy model to quantify the urban sprawl in Cairo city wards (kism).

Deriving the entropy index to compare urban sprawl in the various wards.

It is worthy to mention that in this paper, some local terms (of Arabic origin) are used in the administrative divisions of the Cairo Governorate, they include the following:

Kism = a division (electoral ward) of the city.

\subsection{The Study Area}

Cairo is a historic city, among the earliest settlements along the Nile. Cairo originated on the Nile River banks and now extends over its east bank from Shubra in the north, Heliopolis and Nasr City in the northeast to Helwan in the south [21] (Fahmi and Sutton, 2008). The Giza district lies on the western banks of the Nile extended to the west. Cairo city is part of Greater Cairo Region which comprises Cairo, El Giza, Helwan, Sixth of October and Qalyoubeya (Figure 1). The city is marked by the traditions and influences of the East and the West, the ancient and the modern. However. the city also reflects struggles to cope with problems caused by massive population growth, urban sprawl, and a deteriorating infrastructure. Administratively, the city of Cairo is divided into 31 wards (namely kism) (Figure 1). The city covers an area of more than $453 \mathrm{sq} \cdot \mathrm{km}$, though it is difficult to separate the city from some of its immediate suburbs and bracketed by the desert to the east, south, and west. As the region's principal commercial, administrative and tourist centre, Cairo contains many cultural institutions and encompasses the largest business establishments, governmental offices, universities, hotels and whole 


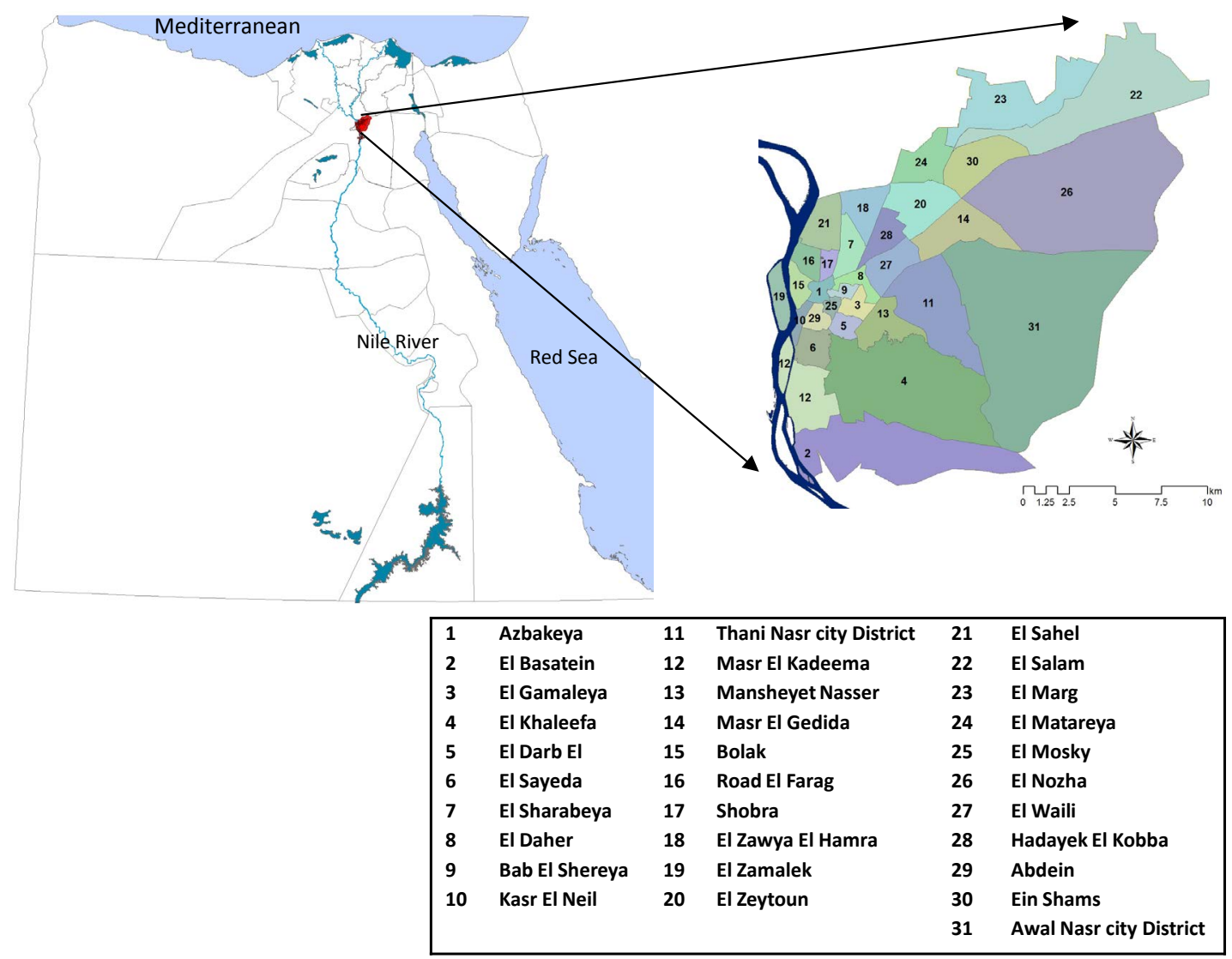

Figure 1. Location of Cairo city, Cairo wards (Kism) and wards boundaries.

markets. The city thus has a dense urban pattern creating constant and temporary activities and jobs attracting population from all over the country. Such conditions lead to high urban growth and sprawl all over the city.

Cairo is known to contain both affluent such as El Zamalek, Masr El Gedida (Heliopols), and non affluent wards such as kism Boulak, kism El Marg, Ein Shams, etc. Demographically, and according to the 2006 census, Cairo city houses 7.79 million of the 18 million population of Greater Cairo Region [22] (CAPMAS, 2006). The natural growth was the main dynamic underlying city growth and an average growth rate of $1.6 \%$ per year. Over the last decade (1996 to 2006) the population growth slowed and the growth rate reached 1.4\% per year [22] [23] (CAPMAS, 2006, 2007). The government's housing policy to provide affordable, viable housing for a significant number of citizens was not efficient and did not succeed which has led many to build homes either semilegally or illegally on privately-owned or public lands. These so-called informal settlements are where approximately 70\% of the inhabitants of Greater Cairo are now living [24] (Howeidy et al. 2009).

In recent years, urban development in desert areas is a main concern of the Egyptian Government. Today, Cairo is surrounded by newly constructed cities namely New Cairo, El Obour, El Sherouk, Badr to the east, 6th of October City, $15^{\text {th }}$ May, El Sheikh Zayed in the south-west. The main aim of the new cities around the Greater Cairo Region (GCR) is to divert the population growth away from the arable land towards the desert to the east and south-west. The first generations of these towns are perceived as economically independent new towns. In 2006 the census recorded only 602,000 people living in the new towns around Cairo, absorbing only 13.8\% of the 3 million people added to all Greater Cairo Region over ten years. At the national level, the population of all Egypt's new towns (20 towns as recorded by the Census in 2006) did not exceed 766,000 persons, about $1.06 \%$ of Egypt's total population [25] (World Bank, 2008).

In Egypt, the urban sprawl is characterized by an increase in building along the highways (Figure 2(a) and Figure 2(b)) and around the urban fringe (Figure 2(c) and Figure 2(d)). The percentage of an area covered by impervious surfaces such as asphalt and concrete is a straightforward measure of development [14] (Barnes et al., 2001). It can be safely considered that developed areas have greater proportions of impervious surfaces. i.e. 

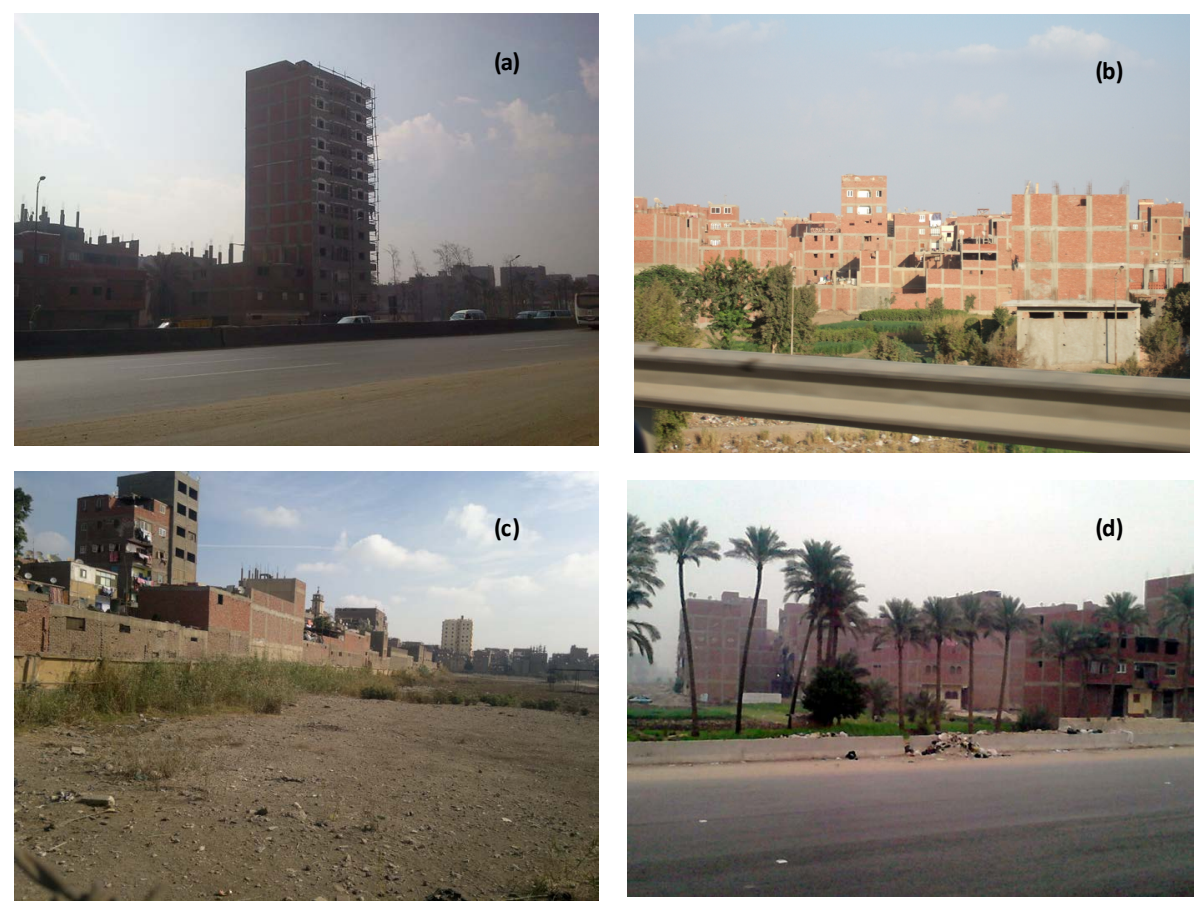

Figure 2. (a) and (b) Urban sprawl along the ring road, Cairo. (c) and (d) photos in Kism El Marg, Cairo for urban sprawl along the city fringe extending on the cultivated lands.

the built-up areas as compared to the lesser-developed areas. Further, the population in the region also influences sprawl. The proportion of the total population in a region to the total built-up of the region is a measure of quantifying sprawl. Considering the built-up area as a potential and fairly accurate parameter of urban sprawl has resulted in making considerable hypothesis on this phenomenon. Since the urban sprawl in Cairo is characterized by an increase in the built-up area along the urban and rural fringe, this attribute gives considerable information for understanding the behavior of such sprawls. This is also influenced by parameters such as population density, population growth rate, etc.

\section{Data Acquisition and Image Processing}

The data collected for this study include multi-temporal satellite data, shape files produced from topographic maps, tables for population data. The data sets and sources are summarized in Table 1.

Table 1. Data used in the current study.

\begin{tabular}{|c|c|c|c|c|c|}
\hline & Data & Scale/resolution & Date Acquired & Data Source & Derivatives \\
\hline 1 & $\begin{array}{c}\text { Landsat TM, ETM+ } \\
\text { (multi-temporal images) }\end{array}$ & $30 \mathrm{~m}$ & $\begin{array}{l}\text { 1984,1990, 2001, } \\
2006,2011,2013\end{array}$ & $\begin{array}{l}\text { Global Land-cover Facility, GLCF } \\
\text { imagery, University of Maryland. }\end{array}$ & $\begin{array}{l}\text { Land-use/land-cover } \\
\text { and Built-up areas }\end{array}$ \\
\hline 2 & Roads and railways (shape file) & $1: 50,000$ & 2012 & $\begin{array}{l}\text { General Organization of } \\
\text { Physical Planning }\end{array}$ & Roads, railways \\
\hline 3 & $\begin{array}{l}\text { Administrative boundaries } \\
\text { (Kism) (shape file) }\end{array}$ & $1: 50,000$ & 2012 & $\begin{array}{l}\text { General Organization } \\
\text { of Physical Planning }\end{array}$ & Cairo wards (Kism) \\
\hline 4 & Population counts (tables) & - & 1986, 1996, 2006 & $\begin{array}{l}\text { Central Agency for Population } \\
\text { Mobilization and Statistics }\end{array}$ & Cairo Wards Population \\
\hline
\end{tabular}

The Landsat TM, ETM were downloaded data type is level 1 meaning that the data product provides systematic radiometric and geometric accuracy, which is derived from data collected by the sensor and spacecraft. The acquired images were all clear with no clouds shadows, due to the arid climate of the region. Atmospheric 
correction was conducted using ENVI 4.8 quick atmospheric correction module as a pre-processing step. The multi-temporal images were co-registered to coordinate system (UTM/WGS84). Landsat TM, ETM images bands 1 - 5 and 7 have a spatial resolution of $30 \mathrm{~m}$, and the thermal infrared band (band 6) has a spatial resolution of $120 \mathrm{~m}$ for Landsat $5 \mathrm{TM}$ images and $60 \mathrm{~m}$ for Landsat $7 \mathrm{ETM}+$ images. The Landsat image were re-sampled using the nearest neighbor algorithm with a pixel size of $30 \mathrm{~m}$ for all bands excluding the thermal band. The resultant root mean square error (RMSE) was found to be less than 0.5 pixels. A subset function was used to limit the scene to the study area. Landsat TM, ETM bands (excluding the thermal) were layers stacked.

\section{Methodology}

To understand the complexity of a dynamic phenomenon such as urban sprawl; land use change analyses, computation of sprawl indicator indices and urban sprawl pattern were determined. The land-use/land-cover, roads network and the city administrative boundaries were used. The steps are explained in this section:

\subsection{Classification of Landsat Mult-Temporal Images}

Medium resolution satellite data acquired from Landsat-5TM and Landsat-7 ETM sensors were used. All bands 1 - 5 and 7 have a spatial resolution of 30 m, within dates (1984, 1990, 2005, 2011 and 2013) for Cairo Governorate. Excluding the thermal band, all bands were stacked and subset to the study area to limit the data size. A supervised signature extraction with the maximum likelihood algorithm was employed to classify the stacked images using ENVI software. The same training dataset were used for the classification of Landsat data in different years. Four land-cover classes were derived: built-up, vegetation, water bodies and desert-bare land. The accuracy of the classified maps was checked with a stratified random sampling method using Envi software. This technique involves dividing the population (the entire classification image or all of the ROIs) into homogeneous subgroups (the individual classes or ROIs) then taking a simple random sample in each subgroup. Two types of Stratified Random sampling are available in ENVI software: proportionate and disproportionate. Proportionate sampling produces sample sizes that are directly related to the size of the classes. Disproportionate sampling allows the user to explicitly define each sample size. The Disproportionate sampling was chosen, a sample size of 20 percent was used. An error matrix (also referred to as confusion matrix or contingency table) is derived from a comparison of reference map pixels to the classified map pixels and is organized as a two dimensional matrix. This matrix takes the form of the columns representing the reference data by category and rows representing the classification by category. We used for reference a topographic map for the city scale 1:5000 and SPOT 4 resolution merged with the panchromatic band.

The built-up class was separated from the multi-temporal classified images. The city electoral wards shape file and the wards population counts tables were obtained from the Central Agency for Public Mobilization and Statistics [22] (CAPMAS, 2007).

\subsection{Calculation of Shannon's Entropy}

The percentage of an area covered by impervious surfaces and concrete is a straightforward measure of urban development [14] (Barnes et al., 2001). Based on this idea, Shannon's Entropy, when integrated with GIS, has proved to be a simple but efficient approach for the measurement of urban sprawl [26] (Shekhar, 2004). Shannon's Entropy (Hn) is used to measure the degree of spatial concentration or dispersion (homogeneity) of a geophysical variable (impervious area) among "n” spatial units [12] (Yeh and Li, 2001; [8] Bhatta et al., 2010; [4] Sudhira et al., 2004).

Shannon's entropy was computed for the current study from the built-up area statistics (wards considered as zones) to detect the urban sprawl phenomenon. Shannon’s entropy (Hn) is given by equation (1) following [12] Yeh and Li (2001)

$$
H_{n}=-\sum P_{i} \log _{e}\left(P_{i}\right)
$$

where $P_{i}$ is the proportion of the variable in the ith zone; $n$ is the total number of zones (wards).

This value ranges from 0 to $\log n$, indicating very compact distribution for values closer to 0 . The values closer to $\log \mathrm{n}$ indicates that the distribution is very dispersed. Larger value of entropy reveals the occurrence of urban sprawl [15] (Sudhira et al., 2004). 


\subsection{Mapping the Entropy Index for Urban Sprawl in Cairo}

Shannon Entropy interpolation methods have been used to create an entropy surface. The methodology is based on [18] Singh (2014). Using ESRI Arc GIS 9.3 Spatial Analyst, the mean entropy value for each ward was assigned to its centroid (center of polygon). Next, an interpolation function was run using the Inverse distance weighted tool (IDW). The Inverse Distance Weighted (IDW) is a method of interpolation that estimates cell values by averaging the values of sample data points in the neighborhood of each processing cell. The closer a point is to the center of the cell being estimated, the more influence, or weight, it has in the averaging process [27] (ESRI ArcGIS 9.3, 2008). These steps were repeated for all five sets of entropy data calculated for the wards in the five investigated years.

\subsection{Regression Analysis}

A regression analysis was conducted as an attempt to study the relationship between urban sprawl (measured by the rate of increase in built-up area, Y) and the annual population growth rate (X). The dependent variable is the built-up area. The Population Growth Rate over the last decade (1996 to 2006) was obtained from the Central Agency for Public Mobilization and Statistics [22] [23] (CAPMAS, 2008a, 2008b). This factor is chosen analysis because it is the main driving force of urban sprawl. Equation (2) was used to calculate the population growth rate and the rate of increase in built-up areas [28] [29] (United Nations Population estimation reports, 2008, 2011)

$$
R=100 \ln \left(P_{2} / P_{1}\right) /\left(t_{2}-t_{1}\right)
$$

$R=$ population growth rate

$t_{2}-t_{1}$ is the time interval (where $t_{2}$ is the later date, $t_{1}$ is the earlier date).

$P_{2}=$ population size (later date)

$P_{1}=$ population size (earlier date)

\section{Results and Discussion}

\subsection{Mapping the Urban Growth in Cairo}

The results of the classified images show that the city experienced rapid intensive urbanization during the period from 1984 to 2013. Accuracy assessment was critical step for a map generated from any remote sensing data. Accuracy assessment of the land use and land cover classification results was obtained by computing Error Matrix in Envi software. The error matrix was used for the analysis (also referred to as confusion matrix or contingency table). An error matrix is derived from a comparison of reference map pixels to the classified map pixels and is organized as a two dimensional matrix. By comparing a classification result with ground truth information, a confusion matrix (contingency matrix) was computed in ENVI. For reference pixels (truth or reference image) we used previously classified images for Cairo in 1984 and 1990 which were available to this study. For the other images, a stratified random derived set of ground truth ROI were used to calculate the accuracy and kappa coefficient. Kappa coefficient, confusion matrix. An overall accuracy of the multi-images ranged between $80.0 \%$ and $94.2 \%$ for the measured years. (The overall accuracy for 1984 is $80.45 \%$, kapa coefficient 0.75 , for 1990 the overall accuracy is $94.25 \%$ with kappa coefficient of 0.92, for 2001 the overall accuracy is 93.35\%, kappa coefficient of 0.91. Finally, for 2006 and 2013 the overall accuracy is 93.35\%, 92.51\% and kappa coefficient is 0.91 and 0.90 respectively). Hence the classification accuracy for the current study seems to be acceptable. Impervious area (built-up area) of Cairo governorate has increased from 156, $3942 \mathrm{~km}^{2}$ in year 1984 to $180,6261 \mathrm{~km}^{2}$ in year 1990 amounting to a 15.5\% of built-up area then. It was noticed in 1990 image the development of a new cultivated land which was given the name "Orabi” in the north-east of Cairo. A rapid urbanization coupled with tremendous growth in the urban class continued and reached 220, $5980 \mathrm{~km}^{2}$ in year 2001 which is a $25.5 \%$ of the built-up area in 1984. The growth in urban areas reaches 231, $2690 \mathrm{~km}^{2}$ for year 2006, amounting to $6.8 \%$ of the total built-up area in the origin year (1984). For the years 2011, the built-up area reached $254,2900 \mathrm{~km}^{2}$ which is equivalent to $14.7 \%$ of the built-up area in 1984 . For 2013 the built-up area measured $285,6402 \mathrm{~km}^{2}$ which is around $20 \%$ of the urban class in 1984. It was noticed in 2013 classified image, a growth of new urban areas around the cultivated land "Orabi” from the west and south sides.

Growth and changes in urban areas are shown in Figure 3(a), Figure 3(b) and Figure 4. 


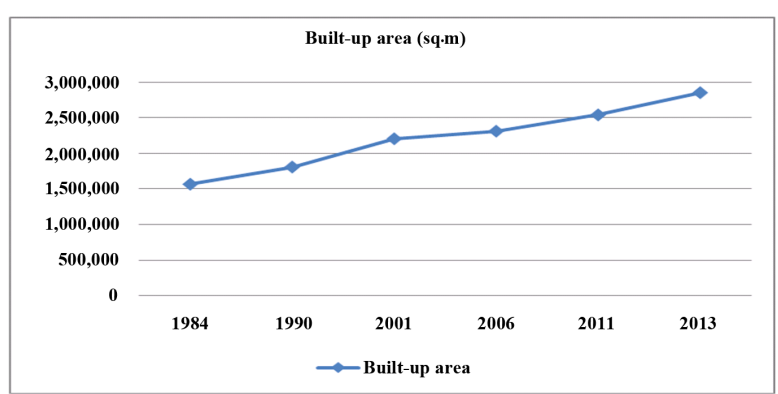

(a)
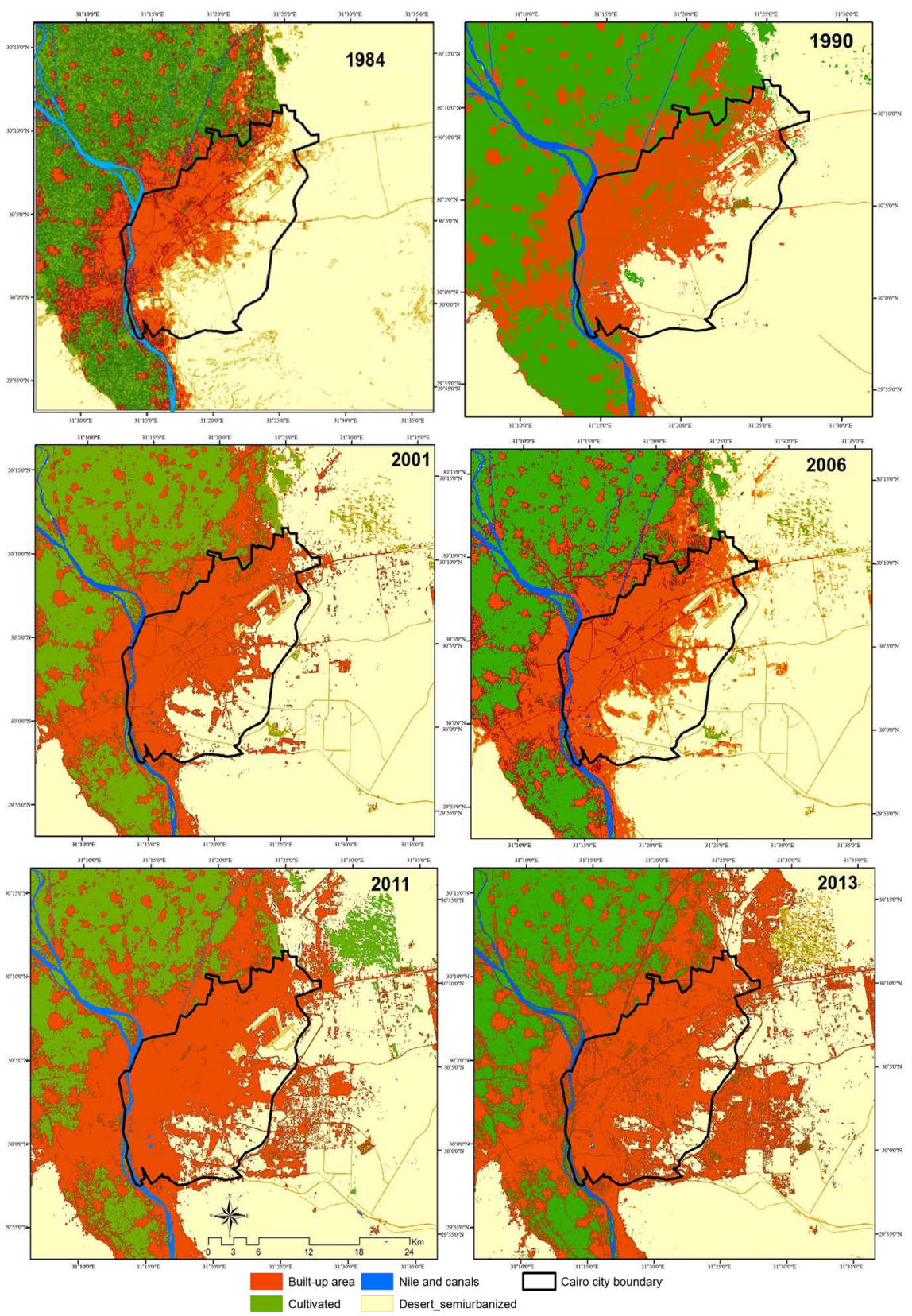

(b)

Figure 3. (a) Trend line showing the growth of built-up area in Cairo from 1984-2013; (b) Land-use/land-cover derived from supervised classification of Landsat TM, ETM images in the years 1984, 1990, 2001, 2006, 2011, 2013. 


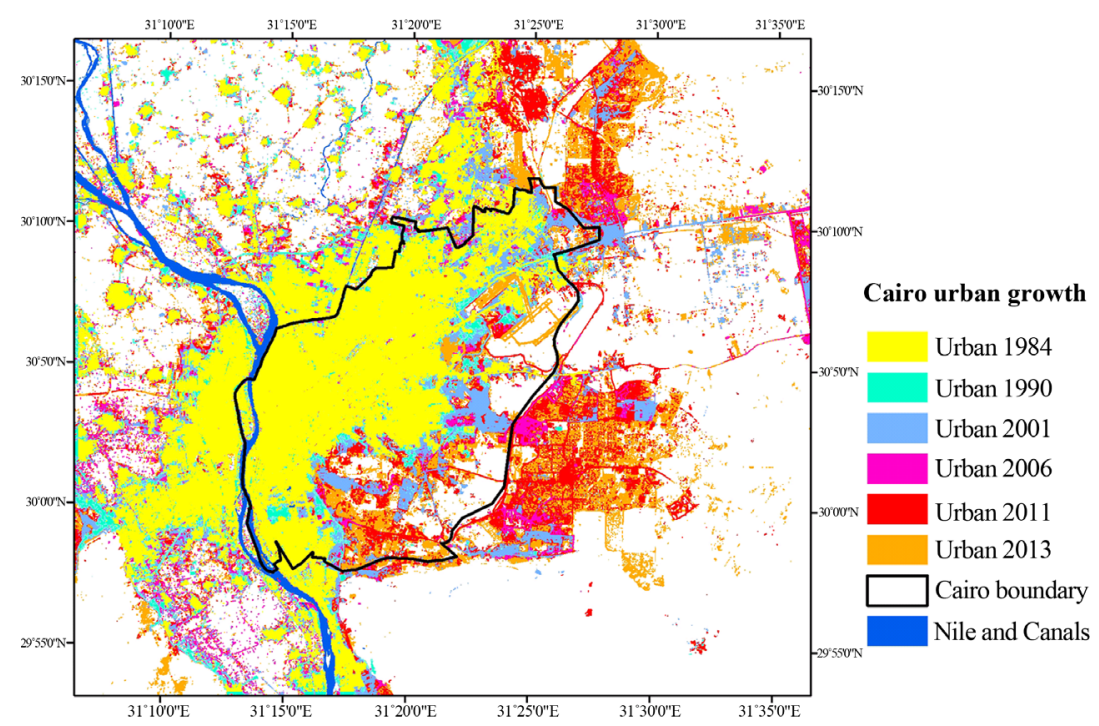

Figure 4. Urban areas in the start year and the changes occurring in Cairo from 1984-2013.

\subsection{Calculation of Shannon's Entropy}

Shannon's entropy was calculated from the built-up area for each ward ( $\mathrm{n}$ is the total number of wards i.e., $\mathrm{n}=31$. The Entropy may range from 0 to $\log n$, indicating a compact distribution of considered phenomenon (urbanization) for values closer to zero and a dispersed distribution for values closer to $\log n$, which indicates occurrence of urban sprawl. Shannon's entropy results for Cairo in the investigated period (1984, 1990, 2001, 2006, 2011 and 2013) are presented in Table 2.

Table 2. (a) Calculation of Shannon's Entropy for Cairo wards (kism); (b) Values of Shannon’s Entropy for the study area for in investigated years.

(a)

\begin{tabular}{|c|c|c|c|c|c|c|c|c|c|c|c|c|c|}
\hline \multirow[t]{2}{*}{ District Name } & \multicolumn{5}{|c|}{ Urban area $\left(\mathrm{Km}^{2}\right)$} & \multicolumn{3}{|c|}{$\begin{array}{l}\text { Area of } \\
\text { Districts }\end{array}$} & \multicolumn{5}{|c|}{$-P_{i} \log _{e} P_{i}$} \\
\hline & 1984 & 1990 & 2001 & 2006 & 2011 & 2013 & $\left(\mathrm{Km}^{2}\right)$ & 1984 & 1990 & 2001 & 2006 & 2011 & 2013 \\
\hline Azbekiya & 1.3907 & 1.3972 & 1.4000 & 1.4374 & 1.4374 & 1.4374 & 1.4383 & 0.0216 & 0.0215 & 0.0216 & 0.022 & 0.022 & 0.022 \\
\hline Kasr El Nile & 1.0091 & 1.0172 & 1.0255 & 1.0411 & 1.0450 & 1.0569 & 1.0923 & 0.0135 & 0.0138 & 0.0139 & 0.014 & 0.0141 & 0.0142 \\
\hline Than Nasr City & 10.7228 & 12.3166 & 13.5628 & 14.2511 & 15.2791 & 16.6348 & 17.3037 & 0.089 & 0.0984 & 0.1055 & 0.1093 & 0.1148 & 0.1218 \\
\hline Masr elkadima & 6.1367 & 8.2223 & 8.8041 & 9.1146 & 9.0291 & 9.2727 & 9.7258 & 0.0584 & 0.0731 & 0.0769 & 0.0789 & 0.0784 & 0.0799 \\
\hline Manshaet Nasser & 3.7836 & 4.4231 & 5.0641 & 5.3197 & 5.3553 & 5.5436 & 5.5540 & 0.0401 & 0.0454 & 0.0505 & 0.0524 & 0.0527 & 0.0541 \\
\hline Misr El Gadida & 8.4813 & 8.6658 & 8.7144 & 8.9915 & 8.9915 & 9.0318 & 9.1543 & 0.0747 & 0.076 & 0.0763 & 0.0781 & 0.0781 & 0.0784 \\
\hline Boulaq & 1.9868 & 1.9879 & 1.9922 & 2.0164 & 2.0165 & 2.0167 & 2.0742 & 0.0239 & 0.0239 & 0.024 & 0.0242 & 0.0242 & 0.0242 \\
\hline Road El Farag & 2.4123 & 2.4282 & 2.4287 & 2.4659 & 2.4666 & 2.4668 & 2.4776 & 0.0282 & 0.0282 & 0.0282 & 0.0285 & 0.0285 & 0.0285 \\
\hline Shubra & 1.3278 & 1.3278 & 1.3278 & 1.3387 & 1.3387 & 1.3387 & 1.3387 & 0.0169 & 0.0172 & 0.0172 & 0.0173 & 0.0173 & 0.0173 \\
\hline El Zamalek & 1.3180 & 1.8332 & 1.9030 & 2.0953 & 2.1221 & 2.2172 & 2.6921 & 0.0169 & 0.0224 & 0.0231 & 0.025 & 0.0252 & 0.0262 \\
\hline El Bassateen & 9.9609 & 11.7734 & 14.4446 & 15.4004 & 18.5778 & 24.7638 & 28.9011 & 0.0842 & 0.0953 & 0.1103 & 0.1154 & 0.1315 & 0.1595 \\
\hline Zaytoun & 7.3405 & 7.6925 & 7.8301 & 7.9087 & 7.9181 & 7.9868 & 8.2066 & 0.0671 & 0.0695 & 0.0704 & 0.071 & 0.071 & 0.0715 \\
\hline El Sahel & 4.9459 & 5.0564 & 5.0570 & 5.1257 & 5.1267 & 5.1322 & 5.2414 & 0.0496 & 0.0504 & 0.0504 & 0.0509 & 0.0509 & 0.051 \\
\hline El Salam & 10.8618 & 13.3474 & 22.1189 & 23.1854 & 25.6253 & 27.9808 & 31.3192 & 0.0898 & 0.1043 & 0.148 & 0.1527 & 0.1631 & 0.1726 \\
\hline El Marg & 9.3025 & 11.6023 & 13.4335 & 14.9724 & 15.4133 & 15.8711 & 16.5368 & 0.0803 & 0.0943 & 0.1048 & 0.1132 & 0.1155 & 0.1179 \\
\hline El Matareya & 5.4220 & 5.8111 & 5.9646 & 6.0471 & 6.0571 & 6.0763 & 6.2273 & 0.0531 & 0.0561 & 0.0573 & 0.0579 & 0.0579 & 0.0581 \\
\hline Al Moski & 0.8037 & 0.8087 & 0.8094 & 0.8103 & 0.8103 & 0.8103 & 0.8103 & 0.0114 & 0.0114 & 0.0114 & 0.0114 & 0.0114 & 0.0114 \\
\hline
\end{tabular}




\begin{tabular}{|c|c|c|c|c|c|c|c|c|c|c|c|c|c|}
\hline Continued & & & & & & & & & & & & & \\
\hline El Gamaleya & 1.8539 & 2.0166 & 2.0267 & 2.0379 & 2.0379 & 2.0418 & 2.0418 & 0.0225 & 0.0242 & 0.0243 & 0.0244 & 0.0244 & 0.0245 \\
\hline Darb Al Ahmar & 1.7451 & 1.8375 & 1.8609 & 1.8624 & 1.8624 & 1.8624 & 1.8624 & 0.0216 & 0.0224 & 0.0227 & 0.0227 & 0.0227 & 0.0227 \\
\hline El Sayeda Zeinab & 3.4664 & 3.5948 & 3.6123 & 3.6304 & 3.6311 & 3.6321 & 3.6443 & 0.0375 & 0.0386 & 0.0387 & 0.0389 & 0.0389 & 0.0389 \\
\hline El Zaher & 1.8728 & 1.9088 & 1.9185 & 1.9664 & 1.9665 & 1.9682 & 1.9700 & 0.023 & 0.0232 & 0.0233 & 0.0237 & 0.0237 & 0.0237 \\
\hline Bab El Shaareya & 0.9749 & 0.9792 & 0.9792 & 0.9792 & 0.9792 & 0.9792 & 0.9792 & 0.0135 & 0.0133 & 0.0133 & 0.0133 & 0.0133 & 0.0133 \\
\hline Zawih ElHamera & 3.6567 & 4.1267 & 4.2606 & 4.5573 & 4.5573 & 4.9519 & 4.9519 & 0.039 & 0.043 & 0.0441 & 0.0465 & 0.0465 & 0.0496 \\
\hline Nozha & 14.5777 & 20.0906 & 26.8897 & 27.9963 & 31.5652 & 34.8543 & 59.7868 & 0.1111 & 0.1387 & 0.1683 & 0.1727 & 0.1863 & 0.198 \\
\hline Wayli & 4.4452 & 4.7050 & 4.7661 & 4.8153 & 4.8538 & 4.9379 & 4.9776 & 0.0457 & 0.0477 & 0.0481 & 0.0485 & 0.0488 & 0.0495 \\
\hline Hadayek El Koba & 3.6730 & 3.8694 & 3.8725 & 3.8725 & 3.8904 & 3.9373 & 3.9476 & 0.0394 & 0.0409 & 0.0409 & 0.0409 & 0.041 & 0.0414 \\
\hline Ain Shams & 8.0440 & 8.1905 & 8.2565 & 8.2881 & 8.2903 & 8.2925 & 8.3293 & 0.072 & 0.0729 & 0.0733 & 0.0735 & 0.0735 & 0.0736 \\
\hline Awal nsr city & 15.0012 & 18.0844 & 29.1329 & 31.3884 & 37.6698 & 45.3908 & 73.4770 & 0.1133 & 0.1291 & 0.1771 & 0.1856 & 0.2075 & 0.2313 \\
\hline Abdin & 0.9749 & 0.9792 & 0.9792 & 0.9792 & 0.9792 & 0.9792 & 1.6877 & 0.0135 & 0.0133 & 0.0133 & 0.0133 & 0.0133 & 0.0133 \\
\hline \multicolumn{8}{|c|}{ Shannon's Entropy $H_{n}$} & 1.4615 & 1.6112 & 1.8154 & 1.8717 & 1.9726 & 2.1023 \\
\hline
\end{tabular}

$\log n=3.4$.

(b)

\begin{tabular}{cc}
\hline Year & Shannon's entropy \\
\hline 1984 & 1.4615 \\
1990 & 1.6112 \\
2001 & 1.8154 \\
2006 & 1.8717 \\
2011 & 1.9726 \\
2013 & 2.1023 \\
& PS: $\log n=3.4$ \\
\hline
\end{tabular}

A dispersed urban growth is revealed by the results of Shannon's entropy (Figure 5). Entropy value has increased from 1.4615 in year 1984 to 1.6112 in year 1990. Further, an increase from 1.6112 in year 1990 to

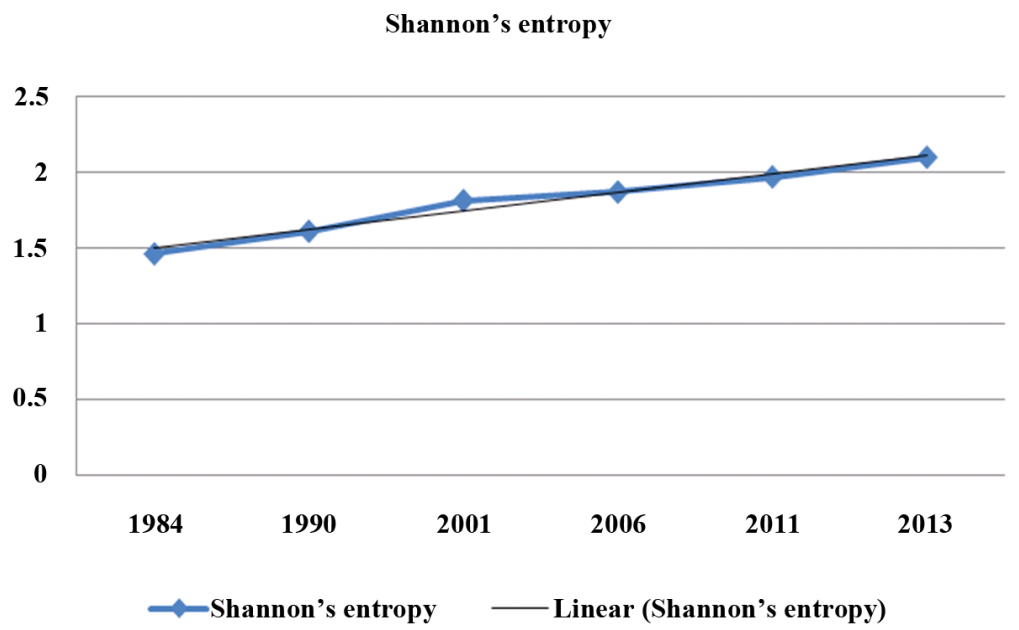

Figure 5. Shannon's Entropy trend line from 1984-2013 indicating an overall more dispersed urban growth during the investigated period. 
1.8154 in year 2001. This increase in value of entropy indicates increase in dispersion of built-up area, which is an indication of urban sprawl. The calculated entropy values are given in Table 2(b). The closer to the upper limit of $(\log n)$ i.e. 3.4 the more dispersion is the built-up area in the region. Higher value of overall entropy for the whole urban area represents higher dispersion of impervious area which is a sign of urban sprawl. Increase in dispersion is due to new areas being added. The higher values of entropy in outer areas indicate more urban sprawl compared to central Cairo. Distribution is predominantly dispersed in outer areas, whereas it is more compact in areas surrounding central Cairo. Hence it can be concluded that Shannon's entropy is a useful and effective tool for identifying the urban sprawl phenomenon in terms of dispersion of the impervious (built-up) area. The difference in entropy between two different periods of time can also be used to indicate the change in the degree of dispersion of land development or urban sprawl [4] (Sudhira et al. 2004).

$$
\begin{aligned}
& \Delta H_{n}=H_{n}(t+1)-H_{n}(t) \\
& \Delta H_{n}=H_{n}(1990)-H_{n}(1984)=1.6112-1.4615=0.1497 \\
& \Delta H_{n}=H_{n}(2001)-H_{n}(1990)=1.8154-1.6112=0.2042 \\
& \Delta H_{n}=H_{n}(2006)-H_{n}(2001)=1.8717-1.8154=0.0563 \\
& \Delta H_{n}=H_{n}(2011)-H_{n}(2006)=1.9726-1.8717=0.1009 \\
& \Delta H_{n}=H_{n}(2013)-H_{n}(2011)=2.1023-1.9726=0.1297
\end{aligned}
$$

\subsection{Creating a Sprawl Entropy Surface for Cairo Wards}

In order to uncover and compare the sprawl pattern in the various city wards, an entropy surface was interpolated for the city during the investigated time period. Such entropy surface (index) is helpful for understanding the temporal and spatial changes in urban growth among the city wards. The surface provides a visual comparison between the various wards. This tool can help decision makers in discussing and analyzing current and future trends and controls for future growth among the wards.

The high entropy values indicate that there is an increase in urban sprawl. The index maps were classified into seven classes. Based on the entropy indices, the pattern of sprawl was examined and the following was deduced:

Cairo City shows a gradual increase in entropy values from the western side towards the east, meaning that the east side of Cairo has the highest urban sprawl. This is because the western side is the old city center, characterized by high density buildings and having scarce vacant lands or pockets. Instead, the urban sprawl takes place vertically (which is a compact growth). Eventually, the highest values of the entropy are found in the eastern wards (kism) namely kism El Nozha and kism Awal-Nasr District, kism Tany-Nasr District, kism El Salam (Figure 6). Such high entropy values are mainly because such districts are more recently urbanized and contains

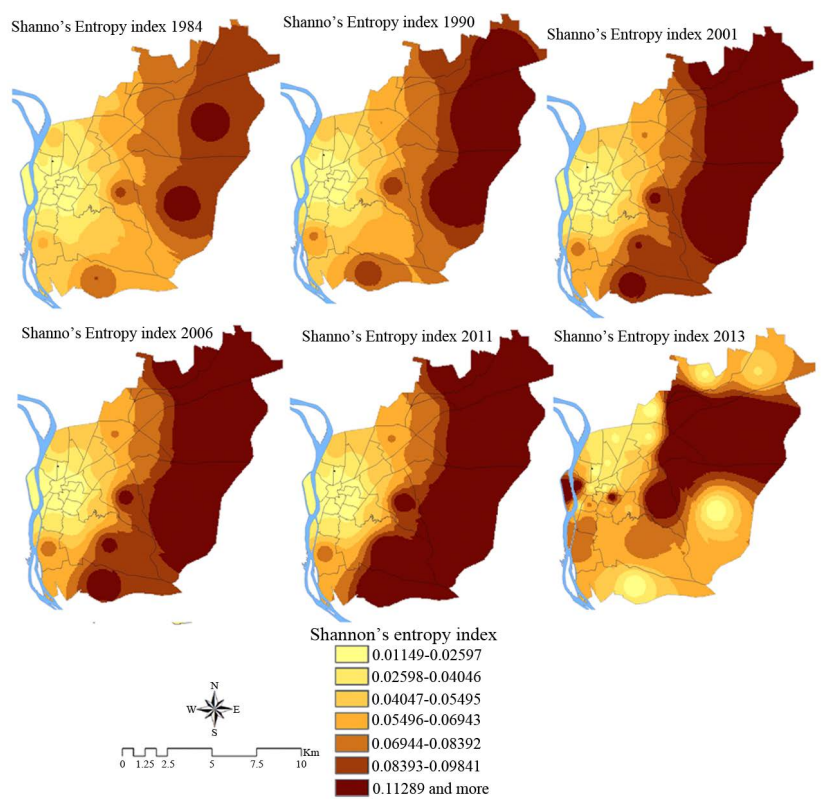

Figure 6. Shannon's Entropy index maps showing the spatial pattern of urban sprawl among the various wards (Kism) in Cairo in the investigated images. 
abundant vacant lands. Further high entropy values were recorded in Kism El Marg which sprawled on arable lands in Cairo fringes and Kism El Bassateen where abundant vacant lands exist around the cemeteries. In 1984, the highest entropy value was 0.1129. Next, comes Kism El Salam. All three divisions lie in the eastern side of Cairo. In 1990, the same three kisms continue to be the highest among all. In addition, two more kisms namely, Kism Thani-Nasr District and El Basateen have higher sprawl. Kism Thani-Nasr District is a growing commercial district attracted more building activities while El Bassateen which is a less affluent district experienced more sprawl in the vacant lands and around the cemeteries. In 2001, it was noticed that sprawl values reached their maximum in two more wards, El Marg and El Khaleefa, El Maadi which again were found to be among the highest in 2006 and 2011 growing on the expense of Cairo fringes and cultivated lands. In 2013, less entropy values were noticed in Kism Awal-Nasr District, Kism El Khalifa and Kism El Basateen indicating a less sprawl. It was also noticed that in the same year, Ksim Thany-Nasr District remained high in entropy values. It was noticed that entropy values increased in kism Ain Shams, Boulak, El Gamaleya, Masr El Gedida, El Zamalek which means that more wards are encountering increased urban sprawl in addition to the ones mentioned earlier.

\subsection{Results of the Regression Analysis}

To understand the dynamics of urban sprawl, it is necessary to analyze the increase in built-up areas. It is worth to visualize the complexity of the urban growth issue in mega cities in vertical and horizontal domains. Yet, detection of the vertical urban that detection of the vertical urban sprawl is not within the scope of this study due to the lack of data such as multi-temporal digital surface models. In order to interpret the regression results, it is quite important to mention such vertical sprawl in our interpretation. The horizontal rate of increase in built-up areas mentioned in Table 3, is considered the independent factor $\mathrm{Y}$ for the simple linear regression analysis. The Population annual growth rate was considered the dependent factor X.

A linear regression analysis was conducted with the 31 observations to model the relationship between the increase in built-up area as the dependent variable $(\mathrm{Y})$ and the independent variable population growth $(\mathrm{X})$. Data was available for the period between 1984 and 2006 and the urban area growth rate (Y) as well as population annual growth rate for the period between 1986 and 2006. A positive linear correlation exists and the linear regression equation is: $\mathrm{Y}=0.308 \mathrm{X}+1.020$. The multiple $\mathrm{R}=0.7530405$ and the coefficient of determination (co-variance) $\mathrm{R}$ square $=0.56707$. The adjusted $\mathrm{R}$ square $=0.55214138$. The significance value $\mathrm{P}$ is 0 $1.01881 \mathrm{E}-06$. The standard error is 0.795172 .

The negative population growth indicates that such wards are experiencing population repulsion and that for a reason or another people are moving from such wards. This result is not surprising, for generally speaking, except for the fringe wards (El Marg and El Bassatein, El Nozha, Thani Nasr City, Awal Nasr City) most of the city wards have scarce vacant lands to sustain new horizontal buildings that fulfills the demand of the young people seeking new homes. Yet, the horizontal built-up areas continue to grow in most of fringe wards (especially in the east). Pockets in older wards were filled by new buildings. Fringe wards with vacant lands (such as El Basatein, El Marg, Awal Nasr City, Thani Nasr City, El Maadi) were subjected to construction of intensive high buildings, thus horizontal and vertical urban growth occurred (formal and non-formal buildings). Old detached houses and low-rise villas were replaced by such high rise buildings. The regression analysis and the regression line (Table 3 and Figure 7) respectively indicate that despite the fact that several wards have negative

Table 3. Population and annual growth rates for Cairo wards during 1986 and 2006.

\begin{tabular}{|c|c|c|c|c|}
\hline \multirow{3}{*}{ Wards } & \multirow{3}{*}{$\begin{array}{c}\text { Population }\left(P_{1}\right) \\
1986\end{array}$} & \multirow{3}{*}{$\begin{array}{c}\text { Population }\left(P_{2}\right) \\
2006\end{array}$} & \multirow{3}{*}{$\begin{array}{l}\text { The population Growth rate } \\
\qquad R=\ln \left(P_{2} / P_{1}\right) / T \times 100\end{array}$} & \multirow{3}{*}{$\begin{array}{l}\text { Urban growth rate } \\
R=\ln \left(P_{2} / P_{1}\right) / T \times 100\end{array}$} \\
\hline & & & & \\
\hline & & & & \\
\hline Misr El Kadema & 254,922 & 217,390 & -0.8 & 1.8 \\
\hline El sayeda zeineb & 199,359 & 132,249 & -2.1 & 0.2 \\
\hline El khlifa & 164,697 & 239,549 & 1.9 & 4.1 \\
\hline Abdeen & 64,949 & 42,223 & -2.2 & 0.0 \\
\hline Elmoski & 43,275 & 22,294 & -3.3 & 0.0 \\
\hline Kasr Elnile & 17,708 & 10,035 & -2.8 & 0.1 \\
\hline
\end{tabular}




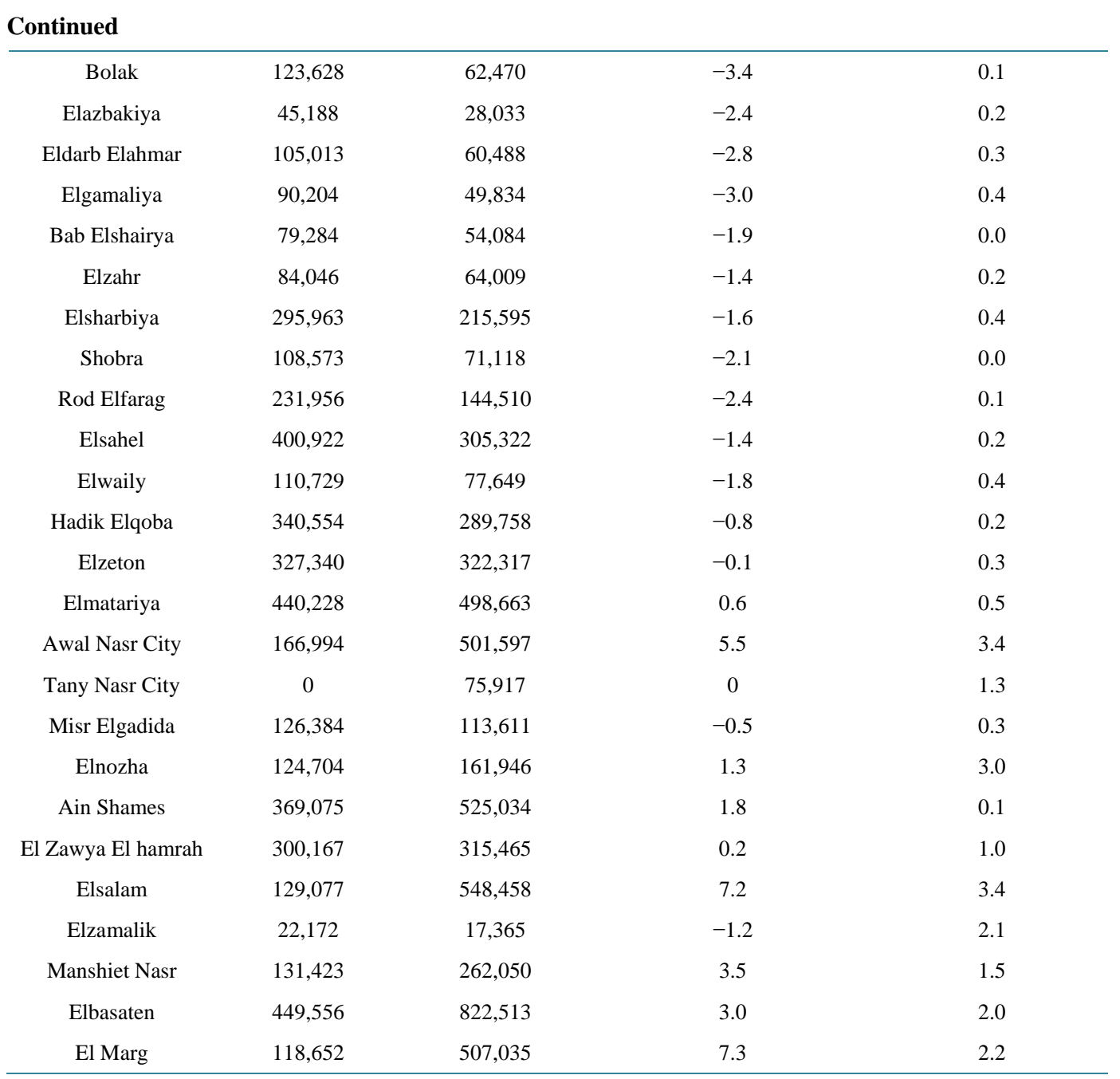

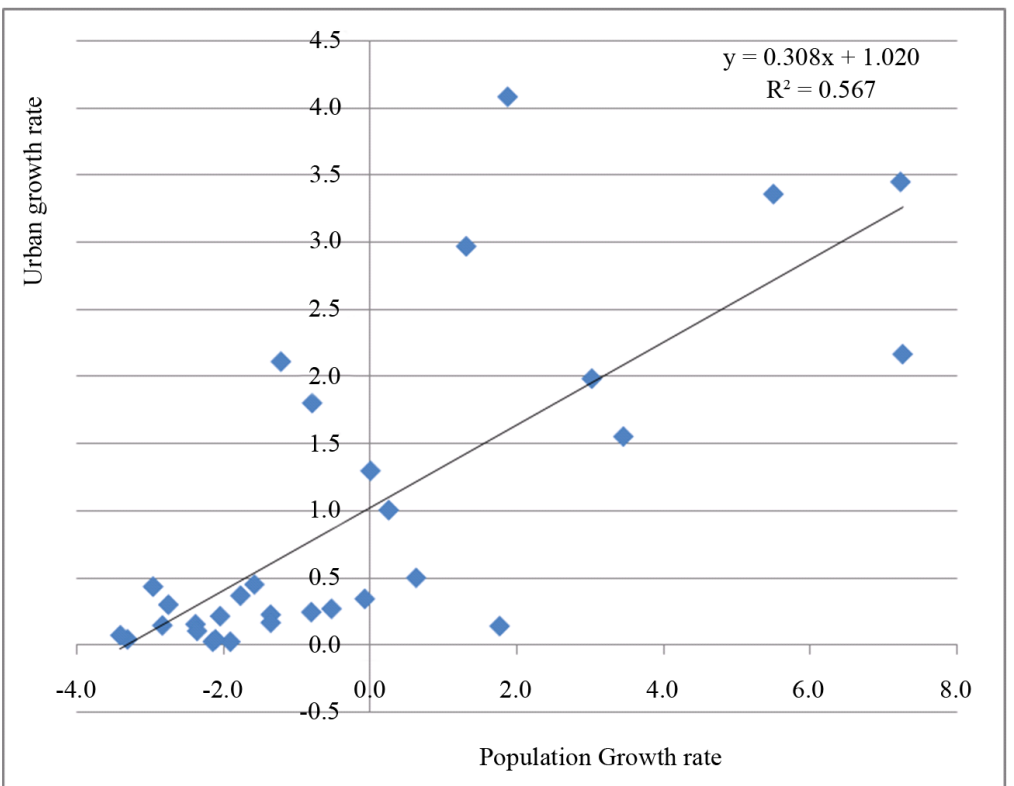

Figure 7. Regression line and equation. 
population growth rates (mostly in the older wards of the west), there is a considerable increase in rate of built-up area (urban growth). This fact can be explained by the continuous replacement of residential building by the business and commercial ones consuming more building footprints and filling the vacant lands (pockets) and increasing the daily commuters trips. Many residents and specifically the new generation living downtown Cairo, sell their apartments/buildings and move to reside in the periphery wards or move to the newly constructed less crowded cities near to Cairo. Due to the enormous rise in prices, such apartments (or buildings) most of them are being assigned to commercial use. It is a fact that commuters' trips to Cairo is of the highest in Egypt, which is a result of business buildings replacing the old residential ones and providing thousands of jobs and/or sources for livelihood. It is a known fact that the population counts in Cairo is much higher during the day than at night. Figure 7 shows some outliers which can be explained by the peripheral wards' growth patterns. Such wards are developed on the bare desert areas surrounding Cairo’s older wards. Such wards (example in El Nozha, Kism Awal Nasr-District, Ksim Thani Nasr-District exhibit intensive investment in construction industry, some of which are meant for loan investment with relatively high prices. Therefore, the built-up areas continue to grow in such wards regardless of the population growth rate.

\section{Summary and Conclusion}

The study defines the sprawl phenomenon by applying a satellite-based change detection analysis and mathematical model using geographic information system. Analysis of multi-temporal Landsat TM satellite images revealed that during the last 30 years, urban areas have expanded by (1.29) $\mathrm{km}^{2}$. The physical expressions and patterns of such urban sprawl on landscapes were measured, mapped, and explained using Shannon’s entropy, remote sensing and geographical information system (GIS).

1) It is deduced from the study, that the urban area expanded in all directions with more development towards the east and north-east directions. This was obvious in 1984 through 2011 image. Relatively lower value of Shannon's entropy (1.4615) in the year 1984 indicates the compact and homogeneous distribution of the built-up area. A more dispersed growth of the built-up area has been observed in recent years, which is also revealed by the results of Shannon's entropy increased values. Entropy value has increased from (1.4615) in year 1984 to (2.1023) in year 2013. These are closer to the upper limit of log n. i.e. (3.40) showing the degree of dispersion of built-up in the region. Larger value of entropy (2.1023) deduced in the year 2013, reveals the occurrence of more urban sprawl in the east wards (Awal Nasr District, Thany Nasr District, El Nozha El Gedida, Ein Shams, El Matareya and Heliopolis) which may be due to the establishment of new residential areas in proximity to the airport area and few commercial centers. For the same year (2013) two wards in the western sides (Bolak and El Gamaleya) experienced high dispersed development. Such wards contain highly crowded markets and workshops and probably tempted the growth of informal urban development during the period following the Egyptian revolution in 2011. This is an impact of the loose control experienced by the local governorates during such politically transitional period.

2) In general, higher entropy values for the city point out higher dispersed growth which is considered a sign of urban sprawl (which is mostly informal urban growth). For the case of Cairo, higher entropy values are recorded in the more recent peripheral wards toward the east and the desert indicating a more sprawl trend compared to central parts (which are the older parts). The western part of Cairo has limited vacant lands and is bordered by the Nile in the west and Nile Delta in the North. The eastern wards namely; Awal Nasr District, Thany Nasr District and El Nozha have vacant lands and growing business centers, and are close to Cairo airport, highways and main ring road to the newly constructed cities surrounding Cairo. Such conditions probably triggered Cairo's urban sprawl towards the east during the study period.

3) Shannon's entropy index is useful in visualizing the spatial distribution and patterns of the urban sprawl. It can be used by decision makers for visualizing, quantify and comparing the urban sprawl phenomenon in cities and its spread among various wards. Such studies could help improving the governmental inspection and control in land-use management plans.

4) The linear regression revealed the relationships between the population growth rate and the urban sprawl among the various wards. For Cairo, the population annual growth rate differs in the various wards. Older western wards are repulsion wards with negative population growth rate. Yet, the need for commercial and business buildings is the main driving force for the increase in built-up areas and therefore contributes positively to the urban sprawl which occurs in all wards. 
5) In this study, some special issues that characterize the city of Cairo are noticed. For most developing countries, each country has its own unique socio-economic problems which influence the housing and urban sprawl patterns in cities. (Typically, the developing countries are faced with an unprecedented population growth, informal urban growth and potentially threatened natural resources). Thus the studies on urban dynamics and changes when conducted in developed countries are not necessarily applicable to developing countries due to the geographic, economic, social and cultural differences. This fact points out the need for more researches in developing countries, each of which should be tailored to the country's environment and city's specific nature and needs. In conclusion, it is recommended to conduct more studies for understanding of the urban sprawl phenomenon and its impacts on the cities of the developing countries.

\section{Acknowledgements}

This work is part of a research project entitled: "Assessment and Detection of Some Triggering factors causing degradation of the urban environment, using multi-temporal data and GIS, case of Cairo city”, supported by the National Authority for Remote Sensing and Space Sciences, NARSS, Cairo, Egypt. The authors acknowledge and appreciate the efforts exerted by Late Prof. Dr. Ossman Abdel Kader Hassan in his contribution to this work.

\section{References}

[1] Brueckner, J.K. (2000) Urban Sprawl, Diagnosis and Remedies. International and Regional Science Review, 23, 160171. http://dx.doi.org/10.1177/016001700761012710

[2] Frenkel, A. and Ashkenazi, M. (2007) The Integrated Sprawl Index: Measuring the Urban Landscape in Israel. Annals of Regional Science, 42, 99-121. http://dx.doi.org/10.1007/s00168-007-0137-3

[3] Knaap, G., Talen, E., Olshansky, R. and Forrest, C. (2013) Government Policy and Urban Sprawl. Illinois Department of Natural Resources, Office of Realty and Environmental Planning, Chicago.

[4] Sudhira, H.S., Ramachandra, T.V. and Jagadish, K.S. (2004) Urban Sprawl: Metrics, Dynamics and Modeling Using GIS. International Journal of Applied Earth Observation and Geoinformatics, 5, 29-39. http://dx.doi.org/10.1016/j.jag.2003.08.002

[5] Kayhko, N. and Skanes, H. (2005) Change Trajectories and key biotopes Assessing landscape dynamics and sustainability. Landscape and Urban Planning, 75, 300-321. http://dx.doi.org/10.1016/j.landurbplan.2005.02.011

[6] Junge, B., Alabi, T., Sonder, K., Marcus, S., Abaidoo, R., Chikoye, D. and Stahr, K. (2009) Use of Remote Sensing and GIS for Improved Natural Resources Management: Case Study from Different Agro Ecological Zones of West Africa. International Journal of Remote Sensing, 31, 6115-6141.

[7] Verzosa, L. and Gonzalez, R. (2010) Remote Sensing and GIS in Monitoring Urban Sprawl: The Case of Baguio City, Philippines. Paper presented at the 1st Seminar on Asian Water Environments. DRMII_05 in CD-ROM, Manila.

[8] Bhatta. B., Saraswati, S. and Bandyopadhyay, D. (2010) Urban Sprawl Measurement from Remote Sensing Data. Applied Geography, 30, 731-740. http://dx.doi.org/10.1016/j.apgeog.2010.02.002

[9] Pocas, I., Cunha, M. and Pereira, L.S. (2011) Remote Sensing Based Indicators of Changes in a Mountain Rural Landscape of Northeast Portugal. Applied Geography, 31, 871-880. http://dx.doi.org/10.1016/j.apgeog.2011.01.014

[10] Batty, M., Xie, Y. and Sun, Z. (1999) The dynamics of urban sprawl. Working Paper Series. Paper 15. Centre for Advanced Spatial Analysis. University College London. http://www.casa.ac.uk/working papers/

[11] Torrens, P.M. and Alberti, M. (2000) Measuring Sprawl. Working Paper No. 27, Centre for Advanced Spatial Analysis, University College London, London. http://www.casa.ac.uk/working_papers/

[12] Yeh, A.G.O. and Li, X. (2001) Measurement and Monitoring of Urban Sprawl in a Rapidly Growing Region Using Entropy. Photogrammetric Engineering and Remote Sensing, 67, 83-90.

[13] Theobald, D.M. (2001) Quantifying Urban and Rural Sprawl Using the Sprawl Index. Proceedings of the Annual Conference of the Association of American Geographers, New York, 2 March 2001.

[14] Barnes, K.B., Morgan III, J.M., Roberge, M.C. and Lowe, S. (2001) Sprawl Development: Its Patterns, Consequences, and Measurement. Towson University. http://pages.towson.edu/morgan/files/Sprawl_Development.pdf

[15] Wei, J., Ma, J., Twibell, R.W. and Underhill, K. (2006) Characterizing Urban Sprawl Using Multi-Stage Remote Sensing Images and Landscape Metrics. Computers, Environment and Urban Systems, 30, 861-879. http://dx.doi.org/10.1016/j.compenvurbsys.2005.09.002

[16] Yu, X.J. and Ng, C.N. (2007) Spatial and Temporal Dynamics of Urban Sprawl along Two Urban-Rural Transects: A Case Study of Guangzhou, China. Landscape and Urban Planning, 79, 96-109. http://dx.doi.org/10.1016/j.landurbplan.2006.03.008 
[17] Schneider, A. and Woodcock, C.E. (2008) Compact, Dispersed, Fragmented, Extensive? A Comparison of Urban Growth in Twenty-Five Global Cities Using Remotely Sensed Data, Pattern Metrics and Census Information. Urban Studies, 45, 659-692. http://landcoverchange.com/wp-content/uploads/2014/09/schneider_woodcock_2008.pdf http://dx.doi.org/10.1177/0042098007087340

[18] Singh, B. (2014) Urban Growth Using Shannon Entropy, a Case Study of Rohtak City. International Journal of Advanced Remote Sensing and GIS International, 3, 544-552.

[19] Denis, E. (1996) Urban Planning and Growth in Cairo. Middle East Report, 202, 7-12. http://dx.doi.org/10.2307/3013031

[20] Denis, E. and Sejourne, M. (2002) ISIS: Information System for Informal Settlements. Ministry of Planning, GTZ, CEDEJ, Cairo.

[21] Fahmi, W. and Sutton, K. (2008) Greater Cairo’s Housing Crisis: Contested Spaces from Inner City Areas to New Communities. Cities, 25, 277-297. http://dx.doi.org/10.1016/j.cities.2008.06.001

[22] Central Agency for Public Mobilization and Statistics (2006) General Census of Population, Housing and Buildings 2006: Final Results. CAPMAS, Cairo.

[23] Central Agency for Public Mobilization and Statistics (2007) Statistical Year Book 2007. CAPMAS, Cairo.

[24] Howeidy, A., Shehayeb, D.K., Goll, E., Abdel Halim, K.M., Séjourné, M., Gado, M., Piffero, E., et al. (2009) Cairo’s Informal Areas between Urban Challenges and Hidden Potentials. http://www.citiesalliance.org/sites/citiesalliance.org/files/CA Docs/resources/Cairo's\%20Informal\%20Areas\%20Betw een\%20Urban\%20Challenges\%20and\%20Hidden\%20Potentials/CairosInformalAreas_fulltext.pdf

[25] World Bank (2008) Egypt Urban Sector: Towards and Urban Sector Strategy. Washington DC. http://books.google.com.eg/books

[26] Shekhar, S. (2004) Urban Sprawl Assessment Entropy Approach. GIS Development, 8, 43-48.

[27] ESRI (2008) Arc GIS, Release 9.3. Environmental Systems Research Institute, Redlands, CA.

[28] United Nations (1983) Manual X: Indirect Techniques for Demographic Estimation. United Nations Sales No. E. 83. XIII. 2, New York. http://www.un.org/esa/population/unpop.htm

[29] United Nations Population Fund-India (2011) Training Manual on Demographic Techniques. 